\title{
Brief analysis of the influence of elements on anaerobic digestion and mathematical model
}

\author{
Rafal Mulka ${ }^{1}$, Xiarong Zheng ${ }^{1}$, Weding Zhang ${ }^{1}$, Baoying Xie ${ }^{1}$, Paul Nyangaresi ${ }^{1}$, Yanmei \\ Zheng ${ }^{1}$, and qingbiao li $^{2}$ \\ ${ }^{1}$ Xiamen University \\ ${ }^{2}$ Affiliation not available
}

May 28, 2020

\begin{abstract}
The main problem during the fermentation process is competition between microorganisms and provision of favorable conditions for archaea. The elements like magnesium, sodium and calcium play an important role during the anaerobic digestion, due to its capability to maintain normal life activities. Besides magnesium can work like effective catalyst during the fermentation process. Therefore, this work reports the influence of the mentioned elements on methane production. Moreover, mathematical model for biogas production for anaerobic digester was presented, which based on a continuous technology. This high-activity and cost-effective mathematical model could improve biogas production efficiency as a tool support for understanding fermentation process.
\end{abstract}

\section{Introduction}

Biogas plants are environmental friendly due to their capability of methane emission reduction. The fermentation process in such biogas plants is a very complex process which can be compared to the digestion process in mammals (e.g. cows and pigs) stomach because during chemical digestion, which occurs in the gastrointestinal tract, food is digest into small molecules by digestive enzymes. Consequently, the biogas plants often use piggery manure ${ }^{1}$ or cattle-manure ${ }^{2}$ as an inoculum. Such material, containing ready culture of bacteria and partially digested, allows the fermentation process in the tank to begin ${ }^{3}$. In addition to the inoculum, temperature (psychrophilic, mesophilic, thermophilic) ${ }^{4}$,total solid ${ }^{5}$, carbon in glucose ${ }^{6}$ and $\mathrm{pH}^{7}$, which influence archaea $^{8}$ survival capability also influence the methane production ${ }^{9}$.

It is known that magnesium (Mg) takes part in some important processes in our life such as carbohydrate and glucose metabolism ${ }^{10}$. The glucose metabolism for the formation of thiamine diphosphate (TDP) from thiamine requires $\mathrm{Mg}^{11}$. Therefore, the microorganisms that are involved in methane production may also need the $\mathrm{Mg}$. For instance, Li et al. reported that magnesium oxide in the co-fermentation process was an effective additive ${ }^{12}$. In another similar study by Wang et al., it was discovered that hydrogen production was linearly increased by using $\mathrm{Mg}$ element ${ }^{13}$. Not only $\mathrm{Mg}$ could have influence on methane production, but other elements like sodium $(\mathrm{Na})$ and calcium $(\mathrm{Ca})$ may also influence this process. This assumption was backed from the previous reports in literature indicating that methane production could be increased by using potassium hydroxide, calcium hydroxide and sodium hydroxide ${ }^{14-17}$.

Besides, the information about influence these elements on methane production can be used for improving efficiency of mathematical model which could be a good tool for biogas plants. Such way could be used for prediction methane production before real production would be started. Unfortunately, many presented 
models took into account not sufficient amount of factors or not crucial factors for methane production. For instance model presented by Masse and Droste contained a large amount of factors like for example: requirement of ammonia- $\mathrm{N}$, total concentration of acetate or rate of hydrolysis. Besides for this model was conducted only few tests and average error for calculation methane production was $28 \%{ }^{9}$. However, most of the studies focused on all four stages ${ }^{18-21}$ (hydrolysis, acidogenesis, acetogenesis, methanogenesis ${ }^{22}$ ). This generate a large amount of variables but it does not guaranty a high model efficiency. For instance model created by Minot included a large amount properties and based on bacterial growth curve ${ }^{23}$. Moreover in this work was found only one sample for testing. Therefore this model cannot be reliable. Similar situation can be found in model presented by P. Axaopoulos and P. Panagakis ${ }^{24}$. Situation looks better for next work, where relative error was smaller than $20 \%{ }^{25}$.

Obviously, the information presented above does not fully describe the factors and models of methane production, but it can be claimed that most of them need very precise information about the process. Besides, because information about the influence of crucial elements during fermentation process is limited, it was decided to extend this knowledge and improve mathematical model. Therefore this study aimed to present mathematical model for continuous technology in biogas plant, which take into account influence of the crucial elements: initial carbon content in the dry mass of the substrate, influence $\mathrm{Mg}$ on methane production, volumetric load, temperature, $\mathrm{pH}$, etc.

\section{Materials and Methodss}

\subsection{Feedstock and inoculum}

The materials used in this study included: grapes, maize and millet, which were collected from the shop in Xiamen city Fujian Province. The straw and grass was collected from village of Xiamen. Dried straws were chopped using a grinder (Hummer 900) to an approximate size of 2-3 $\mathrm{mm}$. Inoculum was obtained from a laboratory-scale working pig manure digester that treated pig wastewater form the same pig farm.

\subsection{Experimental setup and operation}

The methane production from straws and animal manures were determined using a batch method based on the techniques presented by Moller et al. ${ }^{26}$. Each material was tested in duplicate using erlenmeyer flasks with a working volume of $250 \mathrm{~mL}$, then kept at a mesophilic temperature $37^{\circ} \mathrm{C}$. The initial ratio of VS of the substrate to inoculum (S/I) was set to $2: 1$. After mixing the inoculum with the materials in the erlenmeyer flasks, distilled water was added to an effective liquid volume of $200 \mathrm{~mL}$. All the erlenmeyer flasks were tightly closed with rubber septa and foil after being flushed with nitrogen. In ensuring uniform mixing, the reactor contents were shaken every day with continued fermentation for a period of 35 days until no gas production was further observed. The compositions in the different batch set-ups were as follows: The initial VS loading included $15 \mathrm{~g} \mathrm{VS} / \mathrm{L}$ of grapes, millet, maize, grass, and dried straws. The $\mathrm{pH}$ values of the different digester were about 7 . The concentrations of $\mathrm{Mg}, \mathrm{Na}$ and $\mathrm{Ca}$ were determined by inductively coupled plasma-optical emission spectroscopy (ICPOES). The biogas volume (V1) was measured by its displacement of water. The concentration of methane was determined using a gas chromatography with the TDX-01 carbon molecular sieve packing flotation column and high-purity argon as a carrier gas with a flow rate of $35 \mathrm{ml} / \mathrm{min}$. The peak signal was detected by Thermal Conductivity Detector (TCD). The parameters for the instrument were controlled as follows: The temperature of the injection port, the column, the hot wire and the detector was $210,135,175$ and $155{ }^{\circ} \mathrm{C}$, respectively. Meanwhile, the gas injection volume was $100 \mu \mathrm{L}$. The TS and volatile (VS)/TS of the inoculum were $3.41 \%$ and $47.91 \%$, respectively.

\subsection{Data for analysis}

The necessary data needed for the analysis was obtained from the papers ${ }^{27-29}$, dissertation $^{30}$ and from the current conducted experiment in this work (Table S3). The results on methane production for the batch 
system as well as the amount of $\mathrm{Mg}, \mathrm{Na}$ and $\mathrm{Ca}$ in the examined materials, were retrieved from literatures ${ }^{26,31}$. For conducting analysis in these two works, the following materials were used: chicken manure CHM, cattle manure CAM, swine manure SM1 and SM2, corn straw CS and rice straw RS (Table S1). Note that, only mixture of substrates was taken into consideration in a situation where two substrates were used in a codigestion fermentation. Then, the amount of every element was divided by the mass of the mixture. All the elemental contents were first converted to milligram of element per 1 gram of the mixture. The Mg, Na and Ca content in the mixture was established on the basis of the simple equations $1-3$.

$$
\begin{aligned}
& M g=\frac{\sum_{j=1}^{r}\left(I \mathrm{TS}_{j} \bullet \mathrm{Mg}_{j} \bullet M_{j}\right)}{\sum_{j=1}^{r}\left(M_{j}\right)}\left[\frac{\mathrm{mg}}{g}\right](1) \\
& N a=\frac{\sum_{j=1}^{r}\left(I \mathrm{TS}_{j} \bullet \mathrm{Na}_{j} \bullet M_{j}\right)}{\sum_{j=1}^{r}\left(M_{j}\right)}\left[\frac{\mathrm{mg}}{g}\right](2) \\
& C a=\frac{\sum_{j=1}^{r}\left(\mathrm{ITS}_{j} \bullet \mathrm{Ca}_{j} \bullet M_{j}\right)}{\sum_{j=1}^{r}\left(M_{j}\right)}\left[\frac{\mathrm{mg}}{g}\right](3)
\end{aligned}
$$

Where $M$ is the mass of influent material [g]; ITSrepresents fraction of influent dry matter [\%]; $\mathrm{Na}, \mathrm{Mg}$ and $\mathrm{Ca}$ represents the fraction of sodium, magnesium and calcium content in the dry mass of material, respectively [\%]; $j$ is a number of materials, $r$ is a maximum number of materials.

\subsection{Model assumption}

- It was assumed that hydrogen content in the fermenter chamber is sufficient.

- The mixing has no influence.

- The dissociation rate was not taken into account because biogas plant is a large object and a huge amount of material cause very small concentration of the acetic acid. Therefore the dissociation rate is close to 1 and the made mistake is very small too.

- The same difference between the effluent and influent material in fermentation chamber. The influent and effluent of the material is equal.

\subsection{Model description and setup}

The below chemical reactions (reaction 4 and 5), after simplified to the reaction 6 , were used as the based equation in the presenting mathematical model. The production of methane in previous stages were omitted because methane is mainly produced in the last stage (methanogenesis). These equations refer to the hydrolysis, acidogenesis and acetogenesis stages but of course it is a big simplification.

$$
\begin{gathered}
\mathrm{C}_{6} \mathrm{H}_{12} \mathrm{O}_{6} \rightarrow 2 \mathrm{CH}_{3} \mathrm{CH}_{2} \mathrm{OH}+2 \mathrm{CO}_{2}(4) \\
2 \mathrm{CH}_{3} \mathrm{CH}_{2} \mathrm{OH}+\mathrm{CO}_{2} \rightarrow 2 \mathrm{CH}_{3} \mathrm{COOH}+\mathrm{CH}_{4}(5)
\end{gathered}
$$

$6 \mathrm{C} \rightarrow 2 \mathrm{CH}_{3} \mathrm{COOH}(6)$

Then the two below chemical reactions (reaction 7 and reaction 8) are used to calculate total methane production.

$$
\begin{aligned}
& \mathrm{CO}_{2}+4 \mathrm{H}_{2} \rightarrow \mathrm{CH}_{4}+2 \mathrm{H}_{2} \mathrm{O}(7) \\
& \mathrm{CH}_{3} \mathrm{COOH} \rightarrow \mathrm{CH}_{4}+\mathrm{CO}_{2}(8)
\end{aligned}
$$

The previous model based on three phases (log period, exponential phase, stationary phase ${ }^{32}$ ) and it took into account the factors such as: temperature, $\mathrm{pH}$, hydraulic retention time, mass of the substrate, humidity of the mixture, mass of available archaea, specific growth rate, volume of the fermenter, initial carbon content in the dry mass of the substrate, dry mass content in the substrate, content of organic dry matter in the dry mass, initial nitrogen content in the dry mass of the substrate and content of degradable compounds in the dry organic mass. Almost all of them mentioned factors have strong influence on the fermentation process; e.g. humidity of the mixture influence strongly the final methane production. For example, low humidity of 
the mixture inhibits archaea growth. New model for continuous technology based on exponential phase and additionally includes the above mentioned factors and also considered the influence of the followed factors: biogas plant working days, influent of new substrate, chamber volume and sodium, magnesium and calcium content.

\section{Result and discussion}

\subsection{Elements}

\subsection{1. $\mathrm{Mg}$}

The methane production increased slowly with increasing amount of magnesium (Fig. 1). Therefore, $\mathrm{Mg}$ content in the mixture shows to be an important component in the fermentation process. Calculated on the basis of equation 1, the relation between $\mathrm{Mg}$ content and the total methane production in the mixture for a wide range of materials, is evidently linear. The same situation can be observed for the amount group of experimental data.

During fermentation process for bath technology it was observed that smaller $\mathrm{pH}$ cause lower methane production $^{29,33}$. But during experiment it was observed high methane production for mixture, where the initial $\mathrm{pH}$ was lower than it should be. The higher production caused by elements probably occurred because elements like for example magnesium allow to archaea and bacteria to increase their metabolism and create more methane before environmental start to be toxic for them.

\subsection{2. $\mathrm{Na}$}

A relationship between $\mathrm{Na}$ content and the methane yield was found. It can be observed that $\mathrm{Na}$ content in the mixture and total methane production in the mixture, for a wide range of materials, has a linear relationship (Fig. 2). Only two points near the $1 \mathrm{ml} / \mathrm{g}$ methane production were out of the range. The different situation can be observed from the experimental data. It cannot be clearly deduced whether the sodium growth could have some influence on the methane production.

\subsubsection{Ca}

The observed methane production ranging from about $3.5 \mathrm{ml} / \mathrm{g}$ to about $7.5 \mathrm{ml} / \mathrm{g}$ (Fig. 3) had a linear trend. Similar to sodium, only two points near the $1 \mathrm{ml} / \mathrm{g}$ methane production were out of range. From the results, it cannot be strongly confirmed that the increase in the calcium resulted to a higher methane productivity. This is due to the high complexity of the process for the organic matter degradation.

\subsection{Mathematical model}

\subsubsection{Archaea divisions}

The amount of archaea divisions $(\mu)$ per day for bath technology and continuous technology is calculated by using below equation ${ }^{34}$ :

$\mu=\frac{0.693}{50(1.1-W)^{2}}\left[\frac{1}{d}\right](9)$

Where $W$ is the humidity of the mixture, $\mu$ archaea divisions per day. The number $0.693,50$ come from equation which allows to calculate generation time ${ }^{32}$. The value 1.1 allow to check the influence of humidity. Minimum value for this influence is 0.1 . 


\subsubsection{The $\mathrm{pH}$ coefficient}

After new factors were careful analyzed, new equation was created, as shown in equation 10. Because it was proved that greater amount of elements in a mixture cause more production (even when $\mathrm{pH}$ was lower), the new equation modified a little conditions cause by $\mathrm{pH}$. But before equation 10 can be calculated, first, the amount of $\mathrm{Mg}, \mathrm{Na}$, and $\mathrm{Ca}$ in equation 11, 12 and 13 respectively in the mixture of substrates, must be calculated. When the amount of the three elements is known, the coefficient for every element (from equation 11 to 13 ) can then be calculated. The values $0.25,0.2$ and 0.05 was chosen after the test and conclusions - model obtained the best results for these values. The value 3 was used to get the average from the three coefficients.

$E_{\mathrm{pH}}=\mathrm{pH}+\frac{R_{\mathrm{Mg}}+R_{\mathrm{Na}}+R_{\mathrm{Ca}}}{3}(10) R_{\mathrm{Mg}}=(\mathrm{Mg})^{0.05}(11) R_{\mathrm{Na}}=(0.25 \mathrm{Na})^{0.2}(12) R_{\mathrm{Ca}}=(0.25 \mathrm{Ca})^{0.2}$

Where: $R_{\mathrm{Mg}}, \mathrm{R}_{\mathrm{Na}}$ and $\mathrm{R}_{\mathrm{Ca}}$ are the calculated coefficients for the elements, and $\mathrm{E}_{\mathrm{pH}}$ denotes the coefficient for modified $\mathrm{pH}$ value. $\mathrm{Mg}, \mathrm{Na}$ and $\mathrm{Ca}$ is amount of magnesium, sodium and calcium in a mixture [g].

In the next step modified $\mathrm{pH}$ is used for calculations mass of archaea (equation 14).

$M_{\mathrm{pH}}=0.9 e^{-0.5\left(\left|\mathrm{pH}-\left(7.65+E_{\mathrm{pH}}\right)\right|\right)^{2.89}}(14)$

Where, $M_{\mathrm{pH}}$ represents new $\mathrm{pH}$ coefficient. Values -0.5, 2.89 and 7.65 come from previous work ${ }^{34}$.

\subsubsection{The temperature coefficient}

According to results in the literature,equations for the temperature influence were modified. The optimum temperature was changed from $38^{\circ} \mathrm{C}$ to $37{ }^{\circ} \mathrm{C}$ for mesophilic fermentation and from $55{ }^{\circ} \mathrm{C}$ to $54{ }^{\circ} \mathrm{C}$ for termophilic fermentation ${ }^{34}$.

$T_{\mathrm{wsp}}=\frac{1}{1+\left(\frac{T-37}{10}\right)^{2}} T \in\left[25^{\circ} C, 47.5^{\circ} C\right](15)$

$T_{\text {wsp }}=\frac{0.9}{1+\left(\frac{T-54}{9}\right)^{2}} T \in\left(47.5^{\circ} C, 75^{\circ} C\right](16)$

Where, $T_{w s p}$ represents temperature coefficient, $T$ represents temperature in celcious.

\subsubsection{Volumetric load}

The volumetric load is strictly responsible for methane creation during methane production in biogas plant, which used continuous technology. Therefore effect of volumetric load on the process was determined on basis of the available literature knowledge. In available literature it can be found that typical volumetric load range for biogas production was from 2 to $4\left[\mathrm{gVS}(\mathrm{L}[?] \mathrm{d})^{-1}\right]^{28}$. For instance in the work ${ }^{3}$ all experiments were operated at an organic loading rate equal to $[3.5 \mathrm{gVS}(\mathrm{L}[?] \mathrm{d})]^{-1}$.

Theoretically, if volumetric load is bigger than 4, then microorganism cannot use all biomass and convert it in to methane. In the other hand, if this coefficient is lower than 2 , microorganism do not have sufficient amount of organic dry matter, which can be convert in to methane.

Below equation 17 describes volumetric load influence. This equation contains organic dry matter in the biogas plant and allows to simulate the growth of archaea in a water environmental. When the amount of water in fermentator chamber is high then microorganism can growth fast ${ }^{35}$.

$B_{r}=\frac{\sum_{j=1}^{r}\left(M_{j} \bullet \mathrm{ITS}_{j} \bullet \mathrm{IVS}_{j}\right)}{V}\left[\frac{g}{\mathrm{dm}^{3}}\right](17)$

Where, $B_{r}$ represents volumetric load; IVSrepresents influent dry organic matter [\%], $V$ represents tank volume $\left[\mathrm{dm}^{3}\right], j$ is a number of material, and $r$ is a maximum number of materials. 


\subsubsection{Amount of carbon}

The algorithm for estimation carbon amount in mixture can be described as follow (equation 18):

$C^{g}=\frac{\sum_{i=1}^{r}\left(M_{j} \bullet I \mathrm{TS}_{j} \bullet \mathrm{IVS}_{j} \bullet\left(1-U_{j}^{r}\right) \bullet C_{j}^{g}\right)}{\sum_{j=1}^{r}\left(M_{j}\right)}\left[\frac{g}{g}\right](18)$

Where, $C^{g}$, represents initial amount of carbon in a material [\%]; $U_{j}^{r}$, represents content of non-degradable compounds [\%].

\subsubsection{Estimation of methane production}

For biogas plants (continuous technology) methane production is almost constant during production time, therefore parameter ' $k$ ' was describe by using equation 19 . In this equation parameter ' $k$ ' does not change during the process.

$k=T_{\mathrm{wsp}} e^{-2\left(1-M_{\mathrm{pH}}\right)}[-](19)$

The typical archaea growth curve $^{32}$ shows the various stages of the development of archaea but for the continuous production was prepared only one equation which simulate develop of archaea $\left(M_{d}\right)$ in the real biogas plants:

$M_{d}=\min \left(M, \mu M e^{T_{\mathrm{wsp}}}\right)[g](20)$

After parameter ' $k$ ' and 'develop of archaea' are calculated, amount of available carbon (equation 21) and production of acetic acid (equation 22) are calculated. Value 12 is the mass number of carbon $\left(12 \mathrm{~g} \mathrm{~mol}^{-1}\right)$. Number 2 and 6 are the numbers of carbon molecules that take part in chemical reactions (equation 6 ). The number 36 is $12\left(12 \mathrm{~g} \mathrm{~mol}^{-1}\right)$ multiply by 3 . The number 3 was added because from chemical equation 6 it can be seen that from 3 atoms of carbon it can be produced 1 atom of acetic acid. The volumetric load "Br" in the equation estimates amount of carbon, which archaea, processed into methane. For instance if the $\mathrm{Br}$ is equal to 2.5 then $100 \%$ of carbon can be processed into methane. But if the $\mathrm{Br}$ will be lower or higher than 2.5 then the amount of carbon, which can be used by the archaea, will be decreased.

$$
\begin{aligned}
& C_{[i+1]}=\max \left(0, \frac{C_{[i]}+\frac{C^{g} \bullet M_{d}}{12}-6 k \bullet C_{[i]}}{1+\left(\frac{B r-2.5}{6}\right)^{2}}\right)[\mathrm{mol}](21) \\
& H_{[i]}=\{ \\
& \frac{k \frac{C^{g} \cdot M_{d}}{36}}{1+\left(\frac{B r-2.5}{6}\right)^{2}} \quad[\mathrm{~mol}] \quad C_{[i+1]}=0 \\
& 2 k \bullet C_{[i+1]} \quad[\mathrm{mol}] \quad \mathrm{C}_{[i+1]}>0
\end{aligned}
$$

Where, $i$ represents process step, $C$ represents carbon content in the substrate [mol].

Methane production in the large objects like biogas plants can be compared to the microorganism continuous culture. In this kind of culture, livings conditions for microorganism are almost constants. Therefore according to the kinetic equations, which were used for the laboratory scale ${ }^{34}$, it was developed equations which allow to make simulation for archaea growth in biogas plants. For the continuous technology, at the beginning (in the first step) following values: $M_{c h}[1], H_{a}[1], D_{a}$ [1], are equal to zero since those compounds are outcome of following reactions 23,24 and 25 are calculated:

$M_{\mathrm{ch}[i]}=k\left(H_{[i]}+H_{[i]}^{a}\right)(23)$

Where, represents final methane production, $\mathrm{H}$ represents amount of acetic acid, $H^{a}$ represents amount of acetic acid remaining after the processing.

Then it is checked how much carbon dioxide $\left(D^{a}{ }_{[i]}\right)$ and acetic acid $\left(H^{a}{ }_{[i]}\right.$ are left in the anaerobic chamber (equations 25 and 24).

$$
\mathrm{H}_{[i]}^{a}=H_{[i-1]}+H_{[i-1]}^{a}-k\left(H_{[i-1]}+H_{[i-1]}^{a}\right)(
$$


$D_{[i]}^{a}=M_{c h[i-1]}+D_{[i-1]}^{a}-k\left(M_{c h[i-1]}+D_{[i-1]}^{a}\right)$

Then total production of methane $\left(M_{c h}\right)$ (equations 26 and 25) from carbon dioxide $\left(D^{a}{ }_{[\mathrm{i}}\right)$ bonding with hydrogen is summed up with production of methane from acid acetic $\left(H_{[i]}\right)$.

$M=\sum_{i=1}^{n}\left(M_{c h[i]}+k\left(M_{c h[i]}+D_{[i]}^{a}\right)\right)(26)$

\subsection{Verification of the model}

The correctness of the model was estimated with the use of the following measures: relative error of deviations $(\mathrm{Bw})$ defining the difference of the results obtained from the model and tests:

$B w=\frac{100}{n} \sum_{i=1}^{n}\left|\frac{O_{i}-P_{i}}{O_{i}}\right|(27)$

Then the relative root mean square error (RRMSE) ${ }^{36}$ was the next measure method, which checked the relation between the data calculated from the model, the empirical values (RRMSE and CRM test). The closer the result is to 0 , the better the fit of the model to the observed values:

$R R M S E=\frac{\left[\sum_{i=1}^{n}\left(P_{i}-O_{i}\right)^{2} / n\right]^{0.5}}{O}(28)$

$C R M=\frac{\sum_{i=1}^{n} P_{i}}{\sum_{i=1}^{n} O_{i}}(29)$

In the case of the mean absolute error (MAE), the average value of the error produced by the model was examined (equation 30).

$M A E=\frac{\sum_{i=1}^{n}\left(P_{i}-O_{i}\right)}{n}(30)$

Where $P_{i}, O_{i}, \mathrm{n}$ and $O$ represents the predicted data, observed data, amount of data and average from the observed data, respectively.

The group of 35 samples from the literature were examined (Table S1). First, group without the use of new equations were tested (equation from $10-14 ; E_{p h}$ was equal to 0 ). The obtained average error was $23.8 \%$. Then, the same group with the use of new equations were tested. The average error was $5.5 \%$ lower. Therefore, the results presented in table 1 indicate a good prediction. The value of deviations for RRMSE and CRM not greater than 0.3 which indicates a satisfactory fit of the model to the observed values. Besides in table 2, the results for the RRMSE and CRM are much better that in table 1, which indicates an improved. The same situation can be observed for the mean absolute error. Result in the table 2 (267.32) is better than in table 1 (353.44). More details about the results can be found in table S2.

In the case of biogas plants where continuous technology is used the data from pilot study was obtained ${ }^{27,29}$. For the first biogas plant the average error was smaller than $12.5 \%$ and for the second pilot biogas plant the average error was smaller than 21\%. (Fig. 4 and Fig. 5).

\section{Summary}

A mathematical model based mainly on the amount of elements (magnesium, sodium, calcium) in the mixture was presented in this paper. All previous factors, which were included in the further version of the model ${ }^{22}$, were also included. The following conclusions can be drawn on the basis of the analysis and verification of the developed mathematical model:

- The verification of the new equations showed that the developed model is suitability for the prediction of methane yield in the processes of fermentation agricultural substrates. This suitability works with good results under laboratory conditions as well as in agricultural biogas plants applying the continuous technology. 
- The analysis of the impact of magnesium sodium and calcium showed influence of this elements on methane yield.

\section{Suplementary data}

Supporting Information for this article can be found under [Link provided by ........ This section includes additional table with the results [Tables S1].Acknowledgements

This work was supported by National key research and development program (2019YFC1805800), the Science and Technology Project of Xiamen City (3502Z20183009) and the National Natural Science Foundation of China (41641033).

\section{References}

1. Andara RA, Esteban LMJ. Kinetic study of the anaerobic digestion of the solid fraction of piggery slurries. Biomass and Bioenergy. 1999;17:435-443.

2. Müller L, Kretzschmar J, Pröter J, Liebetrau J, Nelles M, Scholwin F. Does the addition of proteases affect the biogas yield from organic material in anaerobic digestion. Bioresource Technology. 2016;203:267-271.

3. Pandey KP, Ndegwa MP, Soupir LM, Alldredge RJ, Pitts JM. Efficacies of inocula on the startup of anaerobic reactors treating dairy manure under stirred and unstirred conditions. Biomass and Bioenergy. 2011;35:2705-2720.

4. S. B. Energie- und Stoffumsetzung in Biogasanlagen - Ergebnisse messtechnischer Untersuchungen an landwirtschaftlichen Biogasanlagen im Rheinland.Institut für Landtechnik. 2005.

5. Ge X, Xu F, Li Y. Solid-state anaerobic digestion of lignocellulosic biomass: Recent progress and perspectives. Bioresource Technology.2016;205:239-249.

6. Muvhiiwa R. F, Hildebrant D, Glasser D, Matambo T, Sheridan C,. A Thermodynamic Approach Toward Defining the Limits of Biogas Production. American Institute of Chemical Engineers. 2015;61:4271 - 4276.

7. Rajagopal R, Masse ID, Singh G. A critical review on inhibition of anaerobic digestion process by excess ammonia. Bioresource Technology. 2013;143:632-641.

8. García-Ruiz M J, Castellano-Hinojosa A, Armato C, González-Martínez A, González-López J, Osorio F. Biogas production and microbial community structure in a stable-stage of a two-stage anaerobic digester. AIChE Journal.2019;66:1-12.

9. Masse DI, Droste RL. Comprehensive model of anaerobic digestion of swine manure slurry in a sequencing batch reactor. Water Resources. 2000;34:3087-3106.

10. Welch AA, Skinner J, Hickson M. Dietary Magnesium May Be Protective for Aging of Bone and Skeletal Muscle in Middle and Younger Older Age Men and Women.Cross-Sectional Findings from the UK Biobank Cohort, Nutrients.2017;9:1189-1205.

11. Maguire D, Talwar D, Shields GP, McMillan D. The role of thiamine dependent enzymes in obesity and obesity related chronic disease states. Clinical Nutrition. 2018;25:8-17.

12. Li J, Huang H, Zhang M, Wang D. Co-fermentation of magnesium oxide-treated corn stover and corn stover liquor for cellulosic ethanol production and techno-economic analysis. Bioresource Technology. 2019;294:74-82.

13. Wang R, Si BH, Wang M, Lin B, Deng PJ, Tan WL, Liu XW, Sun ZX, Teklebrhan T, Tan LZ. Effects of elemental magnesium and magnesium oxide on hydrogen, methane and volatile fatty acids production in in vitro rumen batch cultures. Animal Feed Science and Technology. 2019;294:74-82. 
14. Feng L, Moset V, Li W, Chen C, Möller BH. In-situ injection of potassium hydroxide into briquetted wheat straw and meadow grass - Effect on biomethane production. Bioresource Technology. 2017;239:258265.

15. Jiang D, Ge X, Zhang Q, Zhou X, Zhou C, Keener H. Comparison of sodium hydroxide and calcium hydroxide pretreatments of giant reed for enhanced enzymatic digestibility and methane production. Bioresource Technology.2017;244:1150-1157.

16. Shen J, Zheng Q, Zhang R, Chen C, Liu G. Co-pretreatment of wheat straw by potassium hydroxide and calcium hydroxide: Methane production, economics, and energy potential analysis. Journal of Environmental Management.2019;236:720-726.

17. Yang F, Bai L, Li P, Li Q, Luo L, Li W. Improved methane production and sulfate removal by anaerobic co-digestion corn stalk and levulinic acid wastewater pretreated by calcium hydroxide. Science of the Total Environment. 2019;691:499-505.

18. Bonk F PD, Weinrich S, Sträuber H, Becker D, Kleinsteuber S, Harms H, Centler F. Determination of Microbial Maintenance in Acetogenesis and Methanogenesis by Experimental and Modeling Techniques. Frontiers in Microbiology.2019;10:1-13.

19. H O. Anaerobic Digestion Model No. 1 (ADM1) for mathematical modeling of full-scale sludge digester performance in a municipal wastewater treatment plant.Biodegradation. 2019;30:27-36.

20. Saeed M, Fawzy S, El-Saadawi M. Modeling and simulation of biogas-fueled power system.International Journal of Green Energy. 2018;16:125-151.

21. Saravanan V, Sreekrishnan TR. A mathematical model for a hybrid anaerobic reactor. Journal of Environmental Management. 2008;146:758-761.

22. M S. Anaerobic processes for waste treatment and energy generation. Integrated Waste Management. 2011;2:216-246.

23. Minott JS. Feasibility of fuel cells for energy conversion on the dairy farm. Faculty of the Graduate School of Cornell University. 2002.

24. Axaopoulos P PP, Tsavdaris A, Georgakakis D. Simulation and experimental performance of a solarheated anaerobic digester. Solar Energy. 2001;2:155-164.

25. Vazifehkhoran HA, Triolo MJ. A novel mathematical modelling of waste biomass decomposition to facilitate rapid methane potential prediction. Journal of Cleaner Production. 2008;220:1222-1230.

26. M ller HB, Sommer SG, Ahring BK. . Methane productivity of manure, straw and solid fractions of manure. Biomass Bioenergy. 2004;26:485-495.

27. Stan C, Collaguazo G, Streche C, Apostol T, Cocarta MD. Pilot-Scale Anaerobic Co-Digestion of the OFMSW: Improving Biogas Production and Startup.Sustainability. 2018;10:1-15.

28. Weiland P. Biogas production: current state and perspectives. Appl Microbiol Biotechnol. 2010;85:849860 .

29. Zhou J, Yang J, Yu Qing, Yong X, Xie X, Zhang L, Wei P, Jia H. . Different organic loading rates on the biogas production during the anaerobic digestion of rice straw: A pilot study. Bioresource Technology. 2017;244:865-871.

30. H L. Simulation research on the distribution of C, N and P in the products and by-products of anaerobic digestion. Xiamen University. 2017.

31. Li H, Tan F, Ke L, Xia D, Wang Y, He N, Zheng Y. Mass balances and distributions of C, N, and P in the anaerobic digestion of different substrates and relationships between products and substrates. Chemical Engineering Journal.2016;287:329-336. 
32. Schlegel GH. Mikrobiologia Ogólna. 2003.

33. Ali AH, , Al-Mussawy H A, Ghazal M T, Hamadi N J. Experimental and Theoretical Study for Hydrogen Biogas Production from Municipal Solid Waste. Pollution.2018;5:147-159.

34. Mulka R, Szulczewski W, Szlachta J, Mulka M. Estimation of methane production for batch technology e A new approach. Renewable Energy. 2016;90:440-449.

35. Dahlhoff A. Auswirkungen einer erhöhten Faulraumbelastung auf die Prozessbiologie bei der Vergärung nachwachsender Rohstoffe in landwirtschaftlichen Biogas-anlagen. der Georg-August-Universität Göttingen. 2007.

36. Szulczewski W, Żyromski A, Biniak-Pieróg M, Machowczyk A. Modeling of the effect of dry periods on yielding of spring barley. Agricultural Water Management.2010;97:587-595.
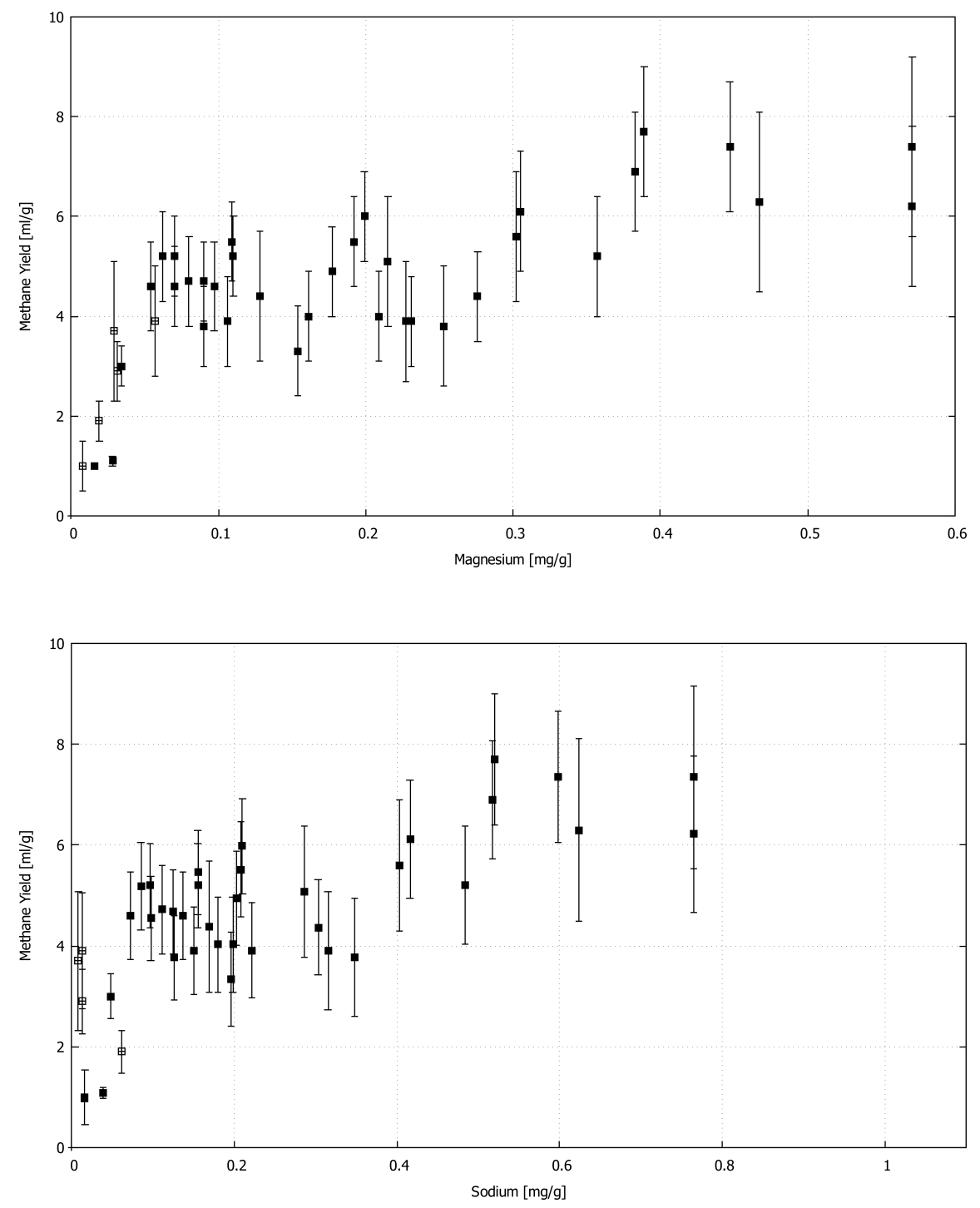

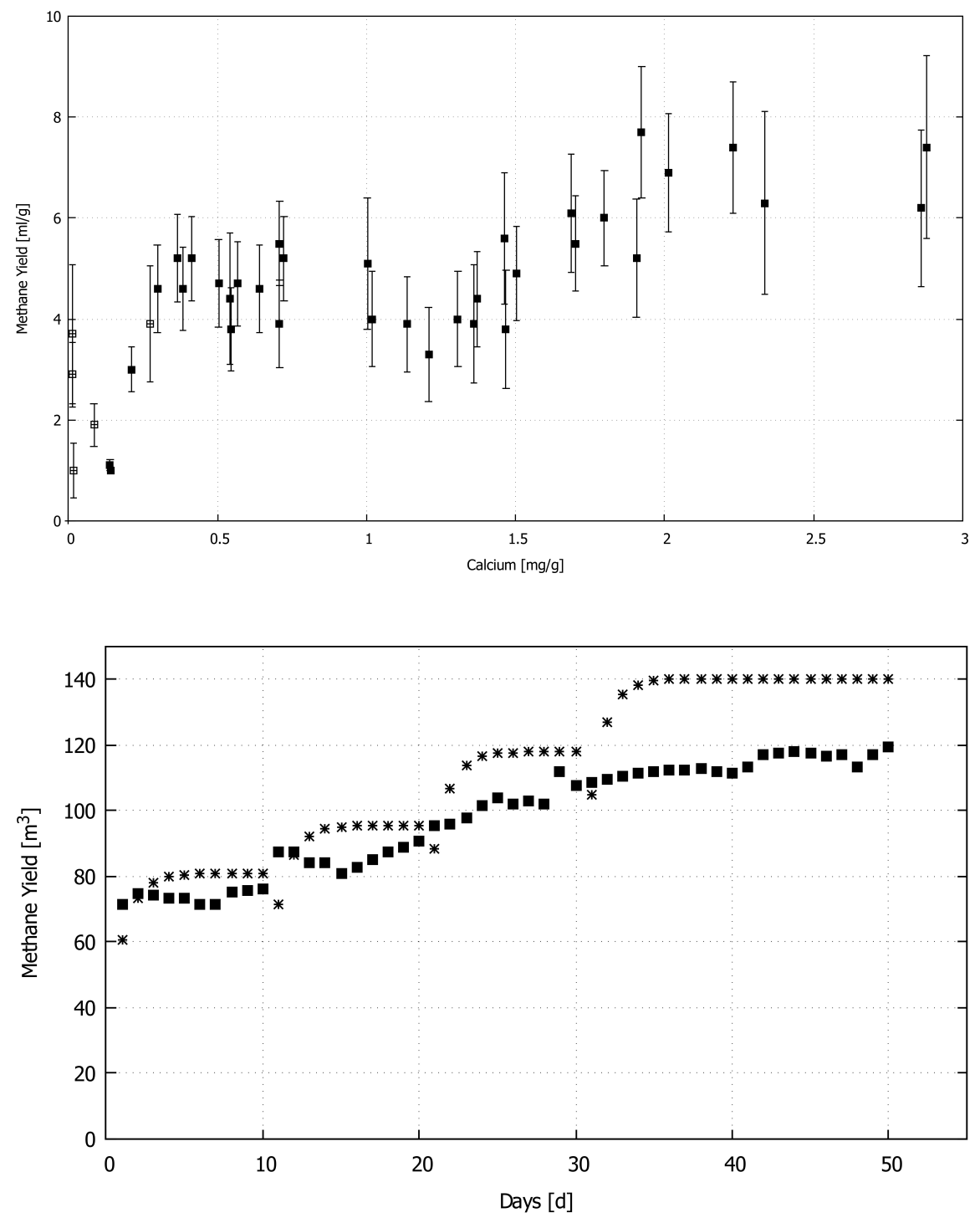


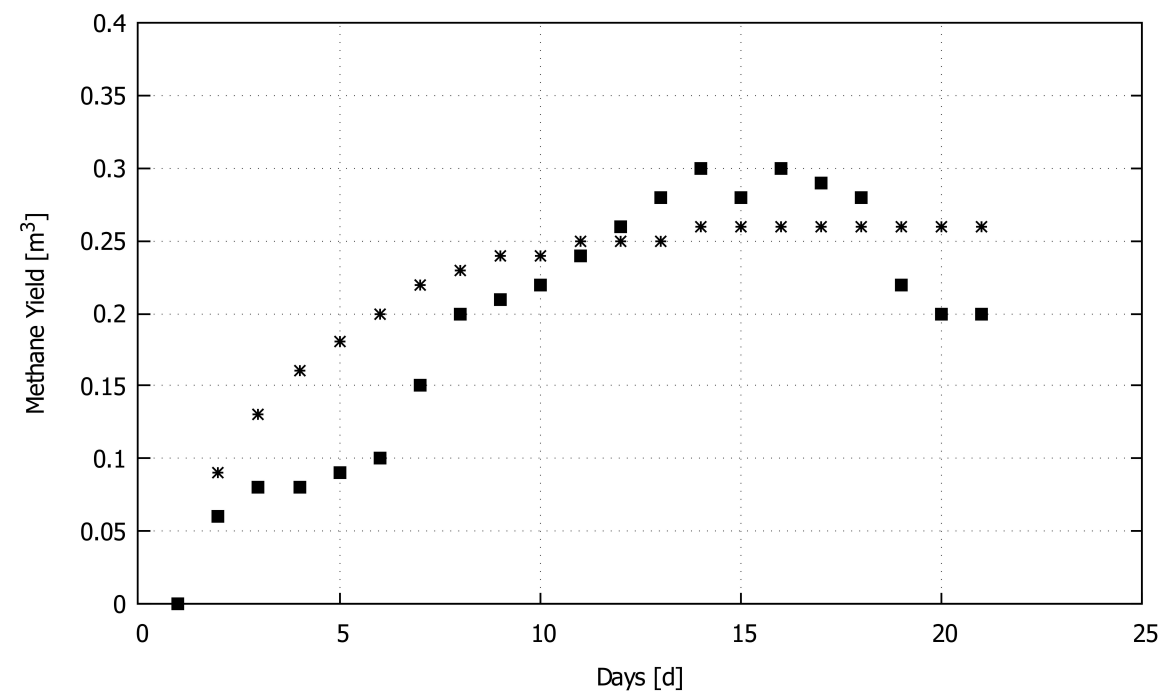

\section{Hosted file}

Table 1 Test results verifying the efficiency of the developed model without inclusion the elements.doc available at https://authorea.com/users/327502/articles/455008-brief-analysis-of-theinfluence-of-elements-on-anaerobic-digestion-and-mathematical-model

\section{Hosted file}

Table 2 Test results verifying the efficiency of the developed model with the elements.docx available at https://authorea.com/users/327502/articles/455008-brief-analysis-of-theinfluence-of-elements-on-anaerobic-digestion-and-mathematical-model 